\title{
Pengaruh kesadaran wajib pajak, sanksi pajak dan kualitas pelayanan terhadap kepuasan wajib pajak bumi dan bangunan
}

\author{
Irfan Fatoni ${ }^{1)}$, Indah Dewi Nurhayati ${ }^{2)}$ \\ Universitas Widyagama Malang
}

\begin{abstract}
Abstrak
Tujuan, -Penelitian ini bertujuan untuk menganalisis efek dari kesadaran wajib pajak, denda pajak dan kualitas layanan otoritas pajak terhadap kepuasan wajib pajak Bumi dan Bangunan di Kota Malang. Desain/Metodologi/Pendekatan, -Penelitian ini menggunakan metode deskriptif dan Populasi dalam penelitian ini di batasi wajib pajak Bumi Dan Bangunan di Kelurahan Tulusrejo Kota Malang dengan sampel sebanyak 98 orang wajib pajak bumi dan bangunan. Teknik pengambilan sampelnya dengan menggunakan simple random sampling.

Temuan Penelitian, -Hasil penelitian ini menunjukkan bahwa kesadaran wajib pajak dan kualitas pelayanan otoritas pajak berpengaruh terhadap kepuasan wajib pajak Bumi dan Bangunan di Kelurahan Tulusrejo.

Orisinalitas/Nilai, - Hasil penelitian memiliki nilai tambah karena kesadaran wajib pajak dan kualitas pelayanan otoritas pajak berpengaruh terhadap kepuasan wajib pajak Bumi dan Bangunan di Kelurahan Tulusrejo secara parsial dan simultan. Tapi, denda pajak tidak berpengaruh pada kepuasan wajib pajak Bumi dan Bangunan di Malang.
\end{abstract}

Kata kunci: Regresi Linier Berganda, Kepuasan pembayar pajak Tanah dan Bangunan, Pajak Tanah dan Bangunan

\section{Impact of taxpayer awareness, tax sanctions and quality of service on the satisfaction of earth and building taxpayers}

\begin{abstract}
Purpose, -This study aims to analyze the effects of taxpayer awareness, tax penalties and the quality of tax authority services on the satisfaction of Earth and Building taxpayers in Malang City. Design/Methodology/Approach, - This study uses descriptive and population methods in this study in the border of Earth and Building taxpayers in Tulusrejo Village of Malang City with a sample of 98 earth and building taxpayers. Sampling technique using simple random sampling.

Findings, -This study show that taxpayer awareness and the quality of service of tax authorities affect the satisfaction of Earth and Building taxpayers in Tulusrejo Village.

Originality/Value, - The results of the study have added value because the awareness of taxpayers and the quality of tax authority services affect the satisfaction of Earth and Building taxpayers in Tulusrejo Village partially and simultaneously. But, the tax penalty has no effect on the satisfaction of earth and building taxpayers in Malang.
\end{abstract}

\section{JMS口}

Received 20 August 2021

Revised 1 Oktober 2021, 15 Oktober 2021, 1 November 2021

Accepted 20 November 2021

Jurnal Manajemen Sains dan Organisasi

Vol 2, No 3, 2021 pp. 178-187

$2685-4724$

2798-9577
Published in the Jurnal Manajemen sains dan Organsasi. Published by FEB UPR Publishing Limited. This article is published under the Creative Commons Attribution (CC BY 4.0) licence. Anyone may reproduce, distribute, translate and create derivative works of this article (for both commercial and non-commercial purposes), subject to full attribution to the original publication and authors. 


\section{Pendahuluan}

Indonesia sebagai negara berkembang yang masih terus melakukan pembangunan pada berbagai sektor dan membutuhkan anggaran yang tidak sedikit. Demi mendukung pembangunan berbagai sektor tersebut, maka diperlukan pembiayaan dari negara. Sumber pembiayaan negara berasal dari sumber daya alam dan sumber daya manusia yang berupa pajak, dimana pajak dijadikan sebagai pilihan utama seiring berkurangnya sumber daya alam (Ayza, 2017). Pajak merupakan iuran pada negara (dapat dipaksakan) yang terutang oleh wajib pajak membayarnya (menurut peraturan) dengan tidak mendapat prestasi kembali yang langsung dapat ditunjuk dan gunanya adalah untuk membiayai pengeluaranpengeluaran umum berhubungan dengan tugas negara untuk menyelenggarakan pemerintahan (Widyaningsih, 2011). Salah satu cara mengoptimalkan penerimaan pajak adalah dengan cara meningkatkan kesadaran wajib pajak dalam membayar Pajak Bumi dan Bangunan. Masalah kesadaran atau kepatuhan masyarakat dalam membayar pajak menjadi masalah klasik yang hampir dihadapi semua negara yang menerapkan sistem perpajakan di negaranya, termasuk di Indonesia.

Tingkat pembayaran pajak bumi dan bangunan di Kota Malang masih mengalami penurunan, hal ini disebabkan terdapat warga yang menunggak pajak Bumi dan Bangunan. Selain masalah belum optimalnya tingkat pembayaran, sanksi keterlambatan pembayaran pajak belum dipertegas batas waktunya yang tepat atau batas akhir keterlambatan pembayaran pajak, sehingga masih terdapat Wajib Pajak Bumi dan Bangunan yang menunggak sampai tahun berikutnya. Selain kesadaran dan sanksi pajak, masalah kualitas pelayanan Pajak Bumi dan Bangunan di Kota Malang juga dapat dikatakan belum optimal. Selain kesadaran Wajib Pajak dan sanksi pajak, kualitas pelayanan dan kepuasan Wajib Pajak berperan penting dalam membayar Pajak Bumi dan Bangunan. Wajib Pajak dalam konteks pelayanan merupakan pelanggan (Customer) pada Birokrasi Perpajakan (Baok et al., 2020).

Berdasarkan latar belakang di atas, penelitian Pengaruh Kesadaran Wajib Pajak, Sanksi Pajak dan Kualitas Pelayanan terhadap Kepuasan Wajib Pajak Bumi Bangunan di Kota Malang dilakukan.

\section{Landasan Teori}

Kesadaran wajib pajak menggambarkan kondisi dimana wajib pajak tersebut memahami dan melaksanakan aturan perpajakan dengan benar dan sukarela (Wella, 2021). Kesadaran ialah hal yang dirasakan atau dialami oleh seseorang atau keadaan mengetahui, sedangkan perpajakan adalah mengenai pajak (Kamus Besar Bahasa Indonesia). Kesadaran perpajakan adalah kerelaan memenuhi kewajiban dan memberikan kontribusi kepada negara yang menunjang pembangunan negara. Tingkat kesadaran wajib pajak tercermin dari pemahaman tentang pajak serta kesungguhan wajib pajak untuk melaporkan dan membayar kewajiban perpajakannya. Apabila pemahaman wajib pajak itu meningkat terhadap fungsi pajak maka wajib pajak akan bersedia membayar pajak dengan kesadarannya sendiri sehingga dengan tingkat kesadaran yang tinggi diharapkan dapat meningkatkan kepatuhan wajib pajak dalam pemenuhan kewajibannya (Baok et al., 2020). Hipotesis yang dapat dirumuskan adalah:

$\mathrm{H}_{1} \quad$ : Kesadaran Wajib Pajak Bumi Dan Bangunan berpengaruh signifikan terhadap kepuasan Wajib Pajak Bumi dan Bangunan.

Sanksi ialah tanggungan (tindakan, hukuman, dan sebagainya) untuk memaksa orang menepati perjanjian atau menaati perjanjian atau menaati ketentuan undang-undang (Kamus Besar Bahasa Indonesia). Sanksi pajak merupakan tindakan yang diberikan kepada wajib pajak ataupun pejabat yang berhubungan dengan pajak yang melakukan pelanggaran baik secara sengaja maupun alpa (Karyadi, 2021). Sanksi pajak merupakan salah satu negara yang mempengaruhi kepatuhan wajib pajak, karena fungsi sanksi adalah digunakan sebagai cara untuk mengatur sekelompok populasi untuk memenuhi aturan yang ditentukan (Yusnidar, 2015). Menurut (Purnamasari et al., 2016), sanksi ditujukan kepada wajib pajak yang tidak mematuhi aturan perpajakan atau melakukan pelanggaran berupa kecurangan terhadap peraturan perpajakan yang berlaku saat ini. Dengan adanya sanksi berupa denda maupun pidana yang cukup tinggi diharapkan wajib pajak lebih patuh terutama dalam hal membayar Pajak Bumi dan Bangunan (PBB). Hipotesis yang dapat dirumuskan adalah:

$\mathrm{H}_{2} \quad$ : Sanksi Pajak Bumi Dan Bangunan berpengaruh signifikan terhadap kepuasan Wajib Pajak Bumi dan Bangunan.

Prinsip - prinsip pelayanan publik berdasarkan Keputusan Menteri Pendayagunaan Aparatur Negara (MenPAN) Nomor 63/KEP/M.PAN/7/2003 (Negara, 2003), yaitu kesederhanaan, kejelasan, kepastian waktu, akurasi, keamanan, tanggung jawab, kelengkapan sarana dan prasarana, kemudahan 
akses, kedisiplinan, kesopanan, keramahan, dan kenyamanan. Kualitas pelayanan berperan sebagai pembanding antara pelayanan yang telah dirasakan konsumen dengan kualitas pelayanan yang diharapkan konsumen (Atarwaman, 2020). Hipotesis yang dapat dirumuskan adalah:

$\mathrm{H}_{3}$ : Kualitas Pelayanan berpengaruh signifikan terhadap kepuasan Wajib Pajak Bumi dan Bangunan.

Ahli pemasaran (Kotler et al., 2016) mengemukakan bahwa pembeli akan puas setelah pembelian tergantung pada kinerja penawaran dan ekspektasi pembeli. "Kepuasan adalah perasaan senang atau kecewa seseorang yang berasal dari perbandingan antara kesannya terhadap kinerja (hasil) suatu produk dan harapan-harapannya." Begitu juga dengan wajib pajak, wajib pajak mengharapkan pelayanan dan kinerja yang baik dari pegawai instansi (Mutia, 2014). Kepuasan pelanggan merupakan evaluasi purna beli, dimana alternatif yang dipilih sekurang-kurangnya sama atau melampaui harapan pelanggan sedangkan ketidakpuasan timbul apabila hasil (outcome) tidak memenuhi harapan.

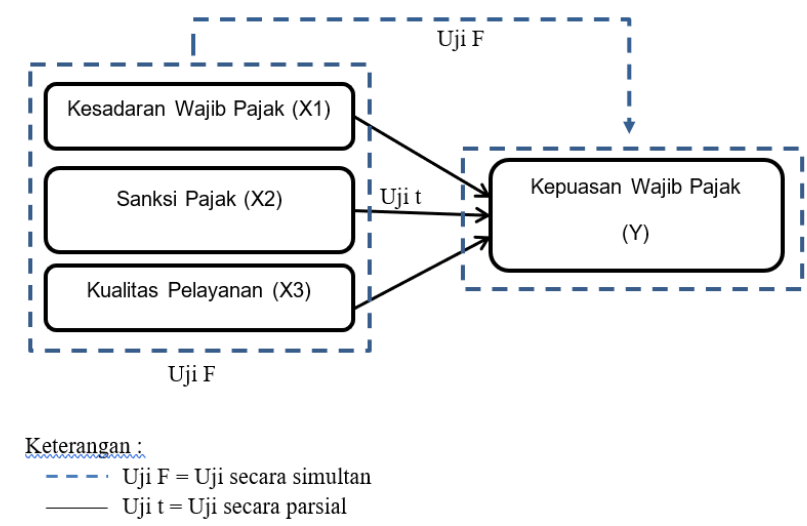

\section{Metode Penelitian}

Penelitian ini menggunakan metode deskriptif dan Populasi dalam penelitian ini di batasi wajib pajak Bumi Dan Bangunan di Kelurahan Tulusrejo Kota Malang. Berdasarkan data yang didapat dari kantor Kelurahan Tulusrejo didapatkan jumlah populasi wajib pajak Bumi Dan Bangunan di sebanyak 4577 KK dan sampel penelitiannya adalah wajib pajak yang melakukan pembayaran Pajak Bumi dan Bangunan (PBB) sebanyak 98 orang. Penghitungan jumlah sampel menggunakan rumus dari Taro Yamane atau Slovin (Rukajat, 2018), dan teknik pengambilan sampelnya dengan menggunakan Simple random sampling.

Definisi operasional dari masing-masing variabel penelitian adalah sebagai berikut :

Tabel 1. Definisi Operasional Variabel

\begin{tabular}{|c|c|c|c|c|c|}
\hline No. & Variabel & Definisi Variabel & Notasi & $\begin{array}{c}\text { Skala } \\
\text { Pengukuran }\end{array}$ & Indikator \\
\hline 1. & $\begin{array}{l}\text { Variabel } \\
\text { Kesadaran } \\
\text { Wajib } \\
\text { Pajak }\end{array}$ & $\begin{array}{l}\text { kesadaran seorang warga } \\
\text { negara untuk membayar } \\
\text { pajak kepada pemerintah. }\end{array}$ & $\mathbf{X}_{1}$ & Ordinal & 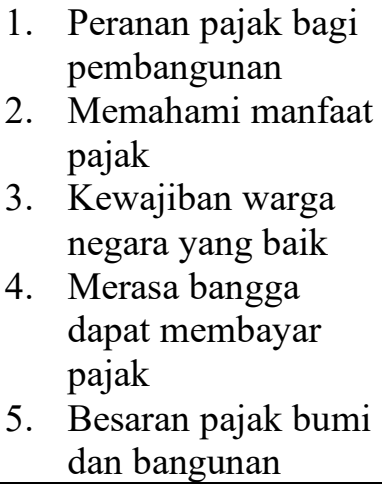 \\
\hline 2. & $\begin{array}{l}\text { Variabel } \\
\text { Sanksi } \\
\text { Pajak }\end{array}$ & $\begin{array}{l}\text { alat pencegah (preventif) } \\
\text { agar wajib pajak tidak } \\
\text { melanggar } \\
\text { perpajakan. }\end{array}$ & $\mathbf{X}_{2}$ & Ordinal & $\begin{array}{l}\text { 1. Pemahaman tentang } \\
\text { sanksi pajak } \\
\text { 2. Besaran sanksi } \\
\text { pajak } \\
\text { 3. Pentingnya sanksi } \\
\text { pajak }\end{array}$ \\
\hline
\end{tabular}




\begin{tabular}{|c|c|c|c|c|c|}
\hline & & & & & $\begin{array}{ll}\text { 4. } & \text { Ketegasan sanksi } \\
\text { pajak } & \\
\text { 5. } & \text { Efek Jera }\end{array}$ \\
\hline 3. & $\begin{array}{l}\text { Variabel } \\
\text { Kualitas } \\
\text { Pelayanan }\end{array}$ & $\begin{array}{l}\text { segala bentuk layanan } \\
\text { umum yang yang } \\
\text { dilaksanakan oleh instansi } \\
\text { pemerintah pusat dan } \\
\text { daerah dan lingkungan } \\
\text { Badan Umum Milik Negara } \\
\text { dalam bentuk barang } \\
\text { maupun jasa. }\end{array}$ & $\overline{X_{3}}$ & Ordinal & $\begin{array}{ll}\text { 1. } & \text { Tampilan Fisik } \\
\text { 2. } & \text { Kehandalan } \\
\text { 3. } & \text { Daya Tanggap } \\
\text { 4. } & \text { Jaminan } \\
\text { 5. } & \text { Empati }\end{array}$ \\
\hline 4. & $\begin{array}{l}\text { Variabel } \\
\text { Kepuasan } \\
\text { Wajib } \\
\text { Pajak }\end{array}$ & $\begin{array}{l}\text { perasaan senang, nyaman } \\
\text { dan lega yang dirasakan } \\
\text { oleh wajib pajak setelah } \\
\text { menunaikan kewajibannya } \\
\text { dalam membayar PBB } \\
\text { kepada Kantor atau Bank } \\
\text { yang melayani } \\
\text { pembayarannya. }\end{array}$ & $Y$ & Ordinal & $\begin{array}{llr}\text { 1. } & \text { Rasa aman atas } \\
\text { kepemilikan bumi } & \\
\text { dan bangunan yang } \\
\text { ditempati } \\
\text { 2. } & \text { Rasa puas atas } \\
& \text { sistem pembayaran } \\
\text { pajak } & \\
\text { 3. Rasa puas atas } & \text { pelayanan yang } \\
\text { diberikan } & \\
\text { pemerintah } & \\
\text { 4. } & \text { Rasa puas atas } \\
\text { sarana dan prasarana } \\
\text { yang dibangun } \\
\text { 5. Rasa puas atas } \\
\text { pemenuhan } \\
\text { kewajiban } \\
\text { pembayaran PBB }\end{array}$ \\
\hline
\end{tabular}

Sumber: Data Primer, 2021

Instrumen yang digunakan dalam penelitian ini adalah angket/kuisioner, dengan memberikan pilihan jawaban yang diukur dengan skala Likert. (Rukajat, 2018).

Tabel 2. Daftar Kriteria Penilaian Jawaban Kuisioner

\begin{tabular}{|c|c|c|}
\hline No & Kriteria/ kategori jawaban & Nilai/ Skor Jawaban \\
\hline 1. & Sangat Setuju & 5 \\
\hline 2. & Setuju & 4 \\
\hline 3. & Biasa/ Netral & 2 \\
\hline 4. & Tidak Setuju & 1 \\
\hline 5. & Sangat Tidak Setuju & \\
\hline
\end{tabular}

Sumber: Herlina, 2019

Data jawaban responden pada penelitian ini masih berskala ordinal sehingga perlu diubah menjadi skala interval dengan Method of Successive Interval (MSI) (Rukajat, 2018).

Model analisis yang digunakan adalah model regresi linier berganda, dengan diawali untuk pengujian validitas dan reliabilitas data serta uji asumsi klasik yang diperlukan. Adapun formulasi model analisnya adalah sebagai berikut:

$Y=\alpha+\beta_{1} X_{1}+\beta_{2} X_{2}+\beta_{3} X_{3}+\varepsilon_{i}$

Keterangan:

$\mathrm{Y} \quad=$ Kepuasan Wajib Pajak

$\alpha \quad=$ Konstanta

$\mathrm{X}_{1} \quad=$ Kesadaran Wajib Pajak

$\mathrm{X}_{2} \quad=$ Sanksi Pajak

$\mathrm{X}_{3} \quad=$ Kualitas Pelayanan

$\beta_{1}, \beta_{2}, \beta_{3}=$ Koefisien arah regresi

$\varepsilon_{\mathrm{i}} \quad=$ Variabel pengganggu diluar model 


\section{Hasil Penelitian}

Jenis kelamin responden

Tabel 3. Karakteristik Responden Berdasarkan pada Jenis Kelamin

\begin{tabular}{|l|c|c|}
\hline \multicolumn{1}{|c|}{ Jenis Kelamin } & Frekuensi & Persentase \\
\hline Perempuan & 54 & 55,1 \\
\hline Laki-laki & 44 & 44,9 \\
\hline \multicolumn{1}{|c|}{ Total } & 98 & 100 \\
\hline
\end{tabular}

Sumber: Data Primer, 2021

Tingkat usia responden

Tabel 4. Karakteristik Responden Berdasarkan pada Usia

\begin{tabular}{|c|c|c|}
\hline Usia & Frekuensi & Persentase \\
\hline 17-35 Tahun & 68 & 69,4 \\
\hline 35-55 Tahun & 18 & 18,4 \\
\hline >55 Tahun & 12 & 12,2 \\
\hline Total & 98 & 100 \\
\hline
\end{tabular}

Sumber: Data Primer, 2021

Pendidikan terakhir responden

Tabel 5. Karakteristik Responden Berdasarkan pada Tingkat Pendidikan Terakhir

\begin{tabular}{|c|c|c|}
\hline Pendidikan Terakhir & Frekuensi & Persentase \\
\hline SMP & 1 & 1 \\
\hline SLTA/SMA/SMK & 24 & 24,5 \\
\hline D1 & 1 & 1 \\
\hline D3 & 5 & 5,1 \\
\hline $\mathrm{D} 4 / \mathrm{S} 1$ & 58 & 59,2 \\
\hline $\mathrm{S} 2$ & 9 & 9,2 \\
\hline Total & 98 & 100 \\
\hline
\end{tabular}

Sumber: Data Primer, 2021

Jenis pekerjaan responden

Tabel 6. Karakteristik Responden Berdasarkan pada Jenis Pekerjaan

\begin{tabular}{|c|c|c|}
\hline Jenis Pekerjaan & Frekuensi & Persentase \\
\hline Karyawan swasta & 35 & 35,7 \\
\hline Pegawai Negeri Sipil & 12 & 12,2 \\
\hline Wiraswasta & 23 & 23,5 \\
\hline Pelajar/ Mahasiswa & 11 & 11,2 \\
\hline Pensiunan & 8 & 8,2 \\
\hline Lainnya & 9 & 9,2 \\
\hline Total & 98 & 100 \\
\hline
\end{tabular}

Sumber: Data Primer, 2021

Jangka waktu lama bekerja responden

Tabel 7. Karakteristik Responden Berdasarkan pada Lama Bekerja

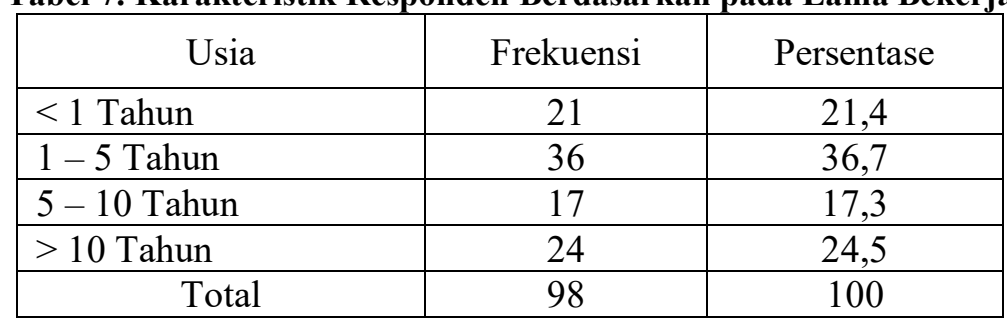

Sumber: Data Primer, 2021 
Tingkat pendapatan per bulan

Tabel 8. Karakteristik Responden Berdasarkan pada Pendapatan Bulanan

\begin{tabular}{|c|c|c|}
\hline Pendapatan Bulanan & Frekuensi & Persentase \\
\hline$<$ Rp 1.000.000,- & 19 & 19,4 \\
\hline Rp 1.000.000,- - Rp. 3.000.000,- & 23 & 23,5 \\
\hline Rp 3.000.001,- - Rp. 5.000.000,- & 21 & 21,4 \\
\hline$>$ Rp. 5.000.000,- & 35 & 35,7 \\
\hline Total & 98 & 100 \\
\hline
\end{tabular}

Sumber: Data Primer, 2021

Kesadaran Wajib Pajak

Tabel 9. Tanggapan Responden terhadap Variabel Kesadaran Wajib Pajak

\begin{tabular}{|l|l|l|l|l|l|l|l|l|}
\hline No. & \multicolumn{1}{|c|}{ Pernyataan } & STS & TS & N & S & SS & $\begin{array}{l}\text { Rata- } \\
\text { Rata }\end{array}$ & Kategori \\
\hline 1. & $\begin{array}{l}\text { Pajak pemasukan daerah sangat } \\
\text { mendukung pemerintah dalam } \\
\text { melaksanakan pembangunan } \\
\text { daerah. }\end{array}$ & 0 & 5 & 6 & 41 & 46 & 4,30 & $\begin{array}{l}\text { Sangat } \\
\text { Setuju }\end{array}$ \\
\hline 2. & $\begin{array}{l}\text { Apakah pajak berkontribusi dalam } \\
\text { perbaikan fasilitas infrastruktur? }\end{array}$ & 1 & 3 & 7 & 51 & 36 & 4,20 & Setuju \\
\hline 3. & $\begin{array}{l}\text { Apakah Saudara merasa puas } \\
\text { dengan fasilitas infrastruktur } \\
\text { seperti jalan, jembatan dan } \\
\text { fasilitas umum yang ada? }\end{array}$ & 8 & 15 & 29 & 32 & 14 & 3,30 & Netral \\
\hline 4. & $\begin{array}{l}\text { Apakah Saudara membayar } \\
\text { kewajiban PBB dengan tepat } \\
\text { waktu? }\end{array}$ & 0 & 3 & 17 & 30 & 48 & 4,25 & $\begin{array}{l}\text { Sangat } \\
\text { Setuju }\end{array}$ \\
\hline 5. & $\begin{array}{l}\text { Apakah Saudara membayar pajak } \\
\text { secara rutin setiap tahun? }\end{array}$ & 4 & 0 & 5 & 39 & 50 & 4,34 & $\begin{array}{l}\text { Sangat } \\
\text { Setuju }\end{array}$ \\
\hline 6. & $\begin{array}{l}\text { Apakah Saudara tidak keberatan } \\
\text { dalam membayar Besaran atau } \\
\text { Nilai Pajak Bumi dan Bangunan } \\
\text { yang dibebankan pada Saudara? }\end{array}$ & 5 & 8 & 15 & 41 & 29 & 3,82 & Setuju \\
\hline Nilai rata-rata item pertanyaan pada variabel Kesadaran Wajib Pajak & & & & & & & & \\
\hline
\end{tabular}

Sumber: Data Primer, 2021

Sanksi Pajak

Tabel 10. Tanggapan Responden terhadap Variabel Sanksi Pajak

\begin{tabular}{|l|l|l|l|l|l|l|l|l|}
\hline No. & \multicolumn{1}{|c|}{ Pernyataan } & $\begin{array}{l}\text { ST } \\
\text { S }\end{array}$ & TS & N & S & SS & $\begin{array}{l}\text { Rata- } \\
\text { rata }\end{array}$ & Kategori \\
\hline 1. & $\begin{array}{l}\text { Apakah Saudara pernah } \\
\text { mendapatkan sosialisasi mengenai } \\
\text { Sanksi Pajak? }\end{array}$ & 18 & 22 & 17 & 22 & 19 & 3,02 & Netral \\
\hline 2. & $\begin{array}{l}\text { Saudara mengetahui besaran atau } \\
\text { nilai sanksi pajak PBB atas } \\
\text { keterlambatan pembayaran. }\end{array}$ & 9 & 11 & 25 & 31 & 22 & 3,47 & Setuju \\
\hline 3. & $\begin{array}{l}\text { Sanksi pajak sangat diperlukan } \\
\text { untuk menertibkan pembayaran } \\
\text { PBB oleh masyarakat. }\end{array}$ & 1 & 2 & 18 & 46 & 31 & 4,06 & Setuju \\
\hline 4. & $\begin{array}{l}\text { Denda pajak 2\% dari besaran PBB } \\
\text { memberikan efek jera bagi Wajib }\end{array}$ & 7 & 20 & 23 & 25 & 23 & 3,38 & Netral \\
\hline
\end{tabular}




\begin{tabular}{|l|l|l|l|l|l|l|l|l|}
\hline & $\begin{array}{l}\text { Pajak yang terlambat membayar } \\
\text { PBB }\end{array}$ & & & & & & & \\
\hline 5. & $\begin{array}{l}\text { Dengan adanya pemutihan pajak, } \\
\text { apakah membuat anda terlambat } \\
\text { untuk membayar Pajak Bumi dan } \\
\text { Bangunan? }\end{array}$ & 31 & 28 & 17 & 13 & 9 & 2,40 & $\begin{array}{l}\text { Tidak } \\
\text { Setuju }\end{array}$ \\
\hline
\end{tabular}

Sumber: Data Primer, 2021

Kualitas Pelayanan

Tabel 11. Tanggapan Responden terhadap Variabel Kualitas Pelayanan

\begin{tabular}{|c|c|c|c|c|c|c|c|c|}
\hline No. & Pernyataan & STS & TS & $\mathrm{N}$ & $\mathrm{S}$ & SS & $\begin{array}{l}\text { Rata- } \\
\text { Rata }\end{array}$ & Kategori \\
\hline 1. & $\begin{array}{l}\text { Apakah Saudara setuju jika loket } \\
\text { pembayaran PBB terdapat pada } \\
\text { masing-masing kantor kelurahan? }\end{array}$ & 1 & 4 & 14 & 32 & 47 & 4,22 & $\begin{array}{l}\text { Sangat } \\
\text { Setuju }\end{array}$ \\
\hline 2. & $\begin{array}{l}\text { Apakah lokasi loket pembayaran } \\
\text { PBB terjangkau dari tempat } \\
\text { tinggal Saudara? }\end{array}$ & 2 & 4 & 13 & 42 & 37 & 4,10 & Setuju \\
\hline 3. & $\begin{array}{l}\text { Apakah Saudara mudah } \\
\text { mendapatkan fasilitas parkir di } \\
\text { kantor/loket pembayaran PBB? }\end{array}$ & 2 & 5 & 25 & 38 & 28 & 3,87 & Setuju \\
\hline 4. & $\begin{array}{l}\text { Apakah Saudara mudah } \\
\text { mendapatkan tempat duduk saat } \\
\text { menunggu antrian di loket } \\
\text { pembayaran PBB? }\end{array}$ & 3 & 3 & 27 & 37 & 28 & 3,86 & Setuju \\
\hline 5. & $\begin{array}{l}\text { Apakah Saudara merasa } \\
\text { termudahkan dengan pembayaran } \\
\text { PBB melalui SPPT online? }\end{array}$ & 2 & 15 & 12 & 26 & 43 & 3,95 & Setuju \\
\hline 6. & $\begin{array}{l}\text { Apakah Saudara menunggu } \\
\text { terlalu lama/ antri saat membayar } \\
\text { PBB? }\end{array}$ & 20 & 39 & 29 & 9 & 1 & 2,30 & $\begin{array}{l}\text { Tidak } \\
\text { Setuju }\end{array}$ \\
\hline 7. & $\begin{array}{l}\text { Apakah petugas pajak merespon } \\
\text { dengan baik saat Saudara } \\
\text { mengajukan komplain mengenai } \\
\text { fasilitas pembayaran PBB (loket } \\
\text { pembayaran, sistem, bukti } \\
\text { pembayaran)? }\end{array}$ & 2 & 7 & 25 & 39 & 25 & 3,79 & Setuju \\
\hline 8. & $\begin{array}{l}\text { Apakah Saudara dilayani dengan } \\
\text { ramah oleh petugas saat } \\
\text { membayar pajak? }\end{array}$ & 0 & 3 & 26 & 39 & 30 & 3,98 & Setuju \\
\hline \multicolumn{7}{|c|}{ ada variabel Kualitas Pela } & 3,76 & Setuju \\
\hline
\end{tabular}

Sumber: Data Primer, 2021

Kepuasan Wajib Pajak

Tabel 12. Tanggapan Responden terhadap Variabel Kepuasan Wajib Pajak

\begin{tabular}{|l|l|l|l|l|l|l|l|l|}
\hline No. & \multicolumn{1}{|c|}{ Pernyataan } & STS & TS & N & S & SS & $\begin{array}{l}\text { Rata- } \\
\text { rata }\end{array}$ & Kategori \\
\hline 1. & $\begin{array}{l}\text { Saudara merasa aman atas } \\
\text { kepemilikan bumi dan bangunan } \\
\text { yang saudara tempati setelah } \\
\text { membayar pajak }\end{array}$ & 0 & 4 & 15 & 33 & 46 & 4,23 & $\begin{array}{l}\text { Sangat } \\
\text { Setuju }\end{array}$ \\
\hline
\end{tabular}




\begin{tabular}{|l|l|l|l|l|l|l|l|l|}
\hline 2. & $\begin{array}{l}\text { Saudara merasa puas dengan sistem } \\
\text { pembayaran pajak yang telah } \\
\text { diterapkan }\end{array}$ & 0 & 3 & 22 & 43 & 30 & 4,02 & Setuju \\
\hline 3. & $\begin{array}{l}\text { Saudara merasa puas atas pelayanan } \\
\text { pajak yang diberikan oleh pemerintah }\end{array}$ & 2 & 4 & 26 & 43 & 23 & 3,83 & Setuju \\
\hline 4. & $\begin{array}{l}\text { Saudara merasa puas dengan sarana } \\
\text { dan prasarana yang dibangun oleh } \\
\text { pemerintah dari pemasukan pajak }\end{array}$ & 6 & 18 & 25 & 31 & 18 & 3,38 & Netral \\
\hline 5. & $\begin{array}{l}\text { Saudara merasa puas karena dapat } \\
\text { memenuhi kewajiban dalam } \\
\text { membayar PBB dengan tepat waktu }\end{array}$ & 1 & 1 & 19 & 35 & 42 & 4,18 & Setuju \\
\hline
\end{tabular}

Sumber: Data Primer, 2021

\section{Pembahasan}

Tabel 13. Model Regresi Linier

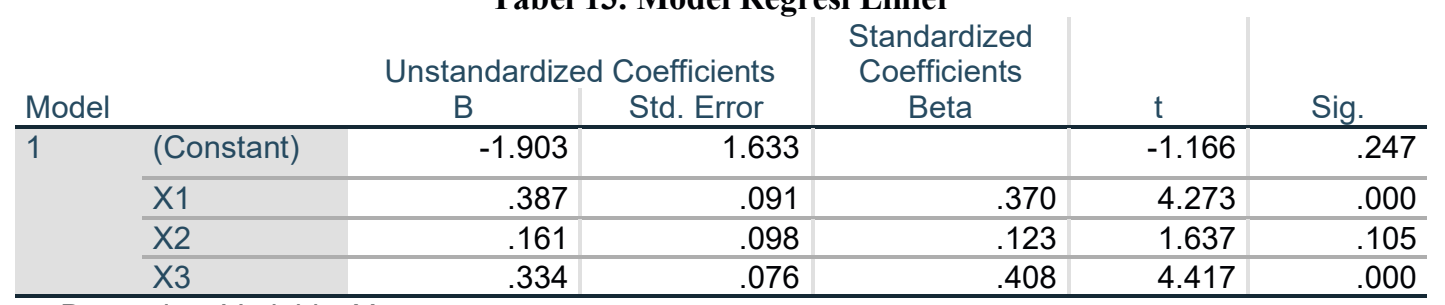

a. Dependent Variable: $Y$

Berdasarkan tabel tersebut diformulasi model regresi penelitian sebagai berikut :

$\mathrm{Y}=-1.903+0.387 \mathrm{X}_{1}+0.161 \mathrm{X}_{2}+0.334 \mathrm{X}_{3}+\varepsilon_{\mathrm{i}}$

Dari model tersebut, diketahui bahwa seluruh variabel bebas penelitian yang meliputi Kesadaran Wajib Pajak, Sanksi Pajak, dan Kualitas Pelayanan berpengaruh terhadap Kepuasan Wajib Pajak Bumi Dan Bangunan.

Hipotesis $\mathbf{H}_{1}$ : Kesadaran Wajib Pajak Bumi Dan Bangunan berpengaruh signifikan terhadap kepuasan Wajib Pajak Bumi Dan Bangunan tidak ditolak, dimana nilai sig.t (0.000) lebih kecil dari alpha penelitian (0.05). Hasil ini sejalan dengan penelitian (Hariyani et al., 2015), (Gusar et al., 2015) dan (Parera \& Erawati, 2017), yaitu semakin tinggi tingkat kesadaran Wajib maka semakin tinggi juga tingkat kepuasan Wajib Pajak. Refleksi kesadaran tersebut seperti memenuhi kewajiban dengan rutin dan tepat waktu membayar. Dengan demikian pajak yang telah dibayarkan dapat dikontribusikan untuk pembangunan daerah dan perbaikan infrastrukstur yang nantinya digunakan oleh Wajib Pajak.

Hipotesis $\mathbf{H}_{2}$ : Sanksi Pajak Bumi Dan Bangunan berpengaruh signifikan terhadap kepuasan Wajib Pajak Bumi Dan Bangunan diolak, karena nilai sig.t (0.105) lebih besar dari alpha penelitian ()$, 05)$. Hasil hipotesis ini sejalan dengan penelitian (Ayunda et al., 2015), tetapi tidak sejalan dengan (Gusar et al., 2015) dan (Parera \& Erawati, 2017). Sanksi Pajak Bumi dan Bangunan sebesar 2\% kurang memberikan efek jera bagi Wajib Pajak yang terlambat membayar Pajak.

Hipotesis $\mathbf{H}_{3}$ : Kualitas pelayanan Pajak Bumi Dan Bangunan berpengaruh signifikan terhadap kepuasan Wajib Pajak tidak ditolak, dimana nilai sig.t (0.000) lebih kecil dari alpha penelitian (0.05). Hasil ini sejalan dengan penelitian (Erawati, 2018), yaitu semakin tinggi kualitas pelayanan pajak maka semakin tinggi juga tingkat kepuasan Wajib Pajak. Jika wajib pajak puas dengan kualitas pelayanan yang disediakan maka kesadaran wajib pajak untuk membayar Pajak semakin meningkat. 
Tabel 14. ANOVA ${ }^{\mathrm{a}}$

\begin{tabular}{|c|c|c|c|c|c|c|}
\hline Model & & Sum of Squares & $\begin{array}{l}\text { 4. Ave } \\
\text { Df }\end{array}$ & Mean Square & $\mathrm{F}$ & Sig. \\
\hline \multirow[t]{3}{*}{1} & Regression & 704.580 & 3 & 234.860 & 45.370 & $.000^{\mathrm{b}}$ \\
\hline & Residual & 486.594 & 94 & 5.177 & & \\
\hline & Total & 1191.174 & 97 & & & \\
\hline
\end{tabular}

Berdasarkan tabel 14 : Anova di atas, pengujian secara bersama-sama (serentak) dari seluruh variabel besa dalam model regresi ini didapatkan nilai sig.F (0.000) lebih kecil dari tingkat alpha penelitian (0.05) artinya Kesadaran Wajib, Sanksi Pajak dan Pelayanan Pajak Bumi Dan Bangunan secara simultan berpengaruh signifikan terhadap Kepuasan Wajib.

\begin{tabular}{|c|c|c|c|c|c|}
\hline \multicolumn{6}{|c|}{ Tabel 15. Kontribusi Relatif } \\
\hline Model & $\mathrm{R}$ & R Square & $\begin{array}{l}\text { Adjusted R } \\
\text { Square }\end{array}$ & $\begin{array}{l}\text { Std. Error of the } \\
\text { Estimate }\end{array}$ & Durbin-Watson \\
\hline 1 & $.769^{a}$ & .592 & .578 & 2.27520 & 2.446 \\
\hline
\end{tabular}

Berdasarkan tabel 15 : Kontribusi Relatif di atas diketahui bahwa kontribusi relatif masing-masing variabel bebas penelitian yang meliputi Kesadaran Wajib, Sanksi Pajak dan Pelayanan Pajak Bumi Dan Bangunan terhadap pencapaian Kepuasan Wajib Pajak sebesar 59,2 \%. Hasil ini menunukan pencapaian yang relatif tinggi dimana variabel bebas penelitian mampu memepengaruhi vaiabel terikat sebesar 59,2 $\%$ dan sisanya sebesar $41,8 \%$ dipengaruhi oleh variabel lain.

\section{Kesimpulan, Saran, dan Keterbatasan Penelitian}

Berdasarkan hasil analisis dari pengolahan data penelitian dapat disimpulkan:

1. Rata-rata jawaban responden atas pertanyaan kuesioner adalah "setuju". Hal ini menunjukkan bahwa responden setuju pentingnya kesadaran Wajib Pajak dalam membayar Pajak, sanki pajak dan kualitas pelayanan Pajak dalam mendukung kepuasan Wajib Pajak.

2. Semakin tinggi tingkat kesadaran Wajib Pajak berdampak semakin tinggi juga tingkat kepuasan Wajib Pajak.

3. Sanksi Pajak kurang memberikan efek jera bagi Wajib Pajak yang terlambat membayar Pajak.

4. Apabila wajib pajak Bumi dan Bangunan diberikan kualitas pelayanan yang baik, mudah, nyaman, serta sistem pembayaran yang aman dalam membayar Pajak maka wajib pajak akan mencapai kepuasan sebagai Wajib Pajak Bumi dan Bangunan.

Berdasarkan kesimpulan hasil penelitian ini didapatkan saran sebagai berikut:

1. Untuk pembuat kebijakan dalam bidang perpajakan sebaiknya memberlakukan sanksi Pajak Bumi dan Bangunan yang lebih tegas dan memberikan efek jera.

2. Untuk peneliti selanjutnya, dapat melakukan analisis dengan menambahkan variabel moderasi untuk lebih menggambarkan variabel kepuasan Wajib Pajak.

Penelitian ini memiliki beberapa keterbatasan sebagai berikut:

1. Penelitian dilakukan di era pandemik Covid-19 sehingga diterapkan protokol kesehatan yang ketat. Peneliti hanya dapat menggunakan metode survei melalui kuesioner (google form) dan tanpa melakukan wawancara, sehingga hasil penelitian yang dikemukakan hanya berdasarkan pada data yang terkumpul melalui instrumen tertulis.

2. Penelitian hanya terbatas pada kelurahan Tulusrejo saja, sehingga kemungkinan jika penelitian ini diterapkan akan menunjukkan hasil yang berbeda pada lokasi dan sampel yang berbeda.

3. Responden mengisi kuisioner dipengaruhi oleh faktor psikologi responden itu sendiri.

\section{Daftar Pustaka}

Atarwaman, R. J. D. (2020). Pengaruh Kesadaran Wajib Pajak, Sanksi Pajak Dan Kualitas Pelayanan Pajak Terhadap Kepatuhan Wajib Pajak Orang Pribadi. Jurnal Akuntansi, 6(1), 39-51.

Ayunda, W. P., Azlina, N., \& Sofyan, A. (2015). Pengaruh sanksi perpajakan, pengetahuan pajak, sikap wajib pajak, dan tingkat ekonomi terhadap kepatuhan wajib pajak dalam membayar pajak 
bumi dan bangunan dengan kontrol petugas kelurahan sebagai variabel moderating di kota pekanbaru. Riau University.

Ayza, B. (2017). Hukum Pajak Indonesia. Kencana.

Baok, R. T. L., Sasongko, T., \& Rifa'i, M. (2020). Strategi Peningkatan Penerimaan Pajak Bumi dan Bangunan (Pbb) di Kota Batu. Reformasi, 10(1), 81-89.

Erawati, T. (2018). pengaruh penerapan efiling terhadap kepatuhan wajib pajak dalam menyampaikan SPT tahunan dengan kepuasan kualitas pelayanan sebagai variabel intervening. Jurnal Akuntansi, $6(1), 1-10$.

Gusar, H. S., Azlina, N., \& Susilatri, S. (2015). Pengaruh Sosialisasi Pemerintah, Pengetahuan Perpajakan, Sanksi Pajak, Kesadaran Wajib Pajak, dan Kualitas Pelayanan Terhadap Kepatuhan Wajib Pajak Dalam Membayar Pajak Bumi dan Bangunan (Kecamatan Bengkong). Riau University.

Hariyani, E., Zirman, Z., \& Kristina, K. (2015). Pengaruh Kesadaran Wajib Pajak, Kualitas Pelayanan, Ketegasan Sanksi dan Kewajiban Moral terhadap Kepatuhan Wajib Pajak dalam Membayar Pajak Reklame (Studi Kasus Dinas Pendapatan Daerah Kota Pekanbaru). Riau University.

KBBI, 2021. Kamus Besar Bahasa Indonesia (KBBI). [Online] Available at: http://kbbi.web.id/ [Diakses 21 Juni 2021]

Karyadi, M. (2021). ANALISIS FAKTOR-FAKTOR YANG MEMPENGARUHI KEPATUHAN WAJIB PAJAK DALAM MEMBAYAR PAJAK BUMI DAN BANGUNAN DI TIGA DESA DI KECAMATAN SURALAGA KABUPATEN LOMBOK TIMUR TAHUN 2019. Journal Ilmiah Rinjani: Media Informasi Ilmiah Universitas Gunung Rinjani, 9(2), 22-34.

Kotler, P., Keller, K. L., Manceau, D., \& Dubois, B. (2016). Marketing Management, 15e édition. New Jersy: Pearson Education.

Mutia, S. P. T. (2014). Pengaruh Sanksi Perpajakan, Kesadaran Perpajakan, Pelayanan Fiskus, Dan Tingkat Pemahaman Terhadap Kepatuhan Wajib Pajak Orang Pribadi (Studi Empiris pada Wajib Pajak Orang Pribadi yang terdaftar di KPP Pratama Padang). Jurnal Akuntansi, 2(1).

Negara, K. M. N. P. A. (2003). Nomor 63/Kep/M. Pan, 7, 2003.

Parera, A. M. W., \& Erawati, T. (2017). Pengaruh kesadaran wajib pajak, sanksi perpajakan, pengetahuan perpajakan, dan pelayanan fiskus terhadap kepatuhan wajib pajak bumi dan bangunan. Jurnal Akuntansi, 5(1), 37-48.

Purnamasari, A., Pratiwi, U., \& Sukirman, S. (2016). Pengaruh Pemahaman, Sanksi Perpajakan, Tingkat Kepercayaan Pada Pemerintah Dan Hukum, Serta Nasionalisme Terhadap 22 Kepatuhan Wajib Pajak Dalam Membayar Pbb-P2 (Studi Pada Wajib Pajak Pbb-P2 Di Kota Banjar). Jurnal Akuntansi Dan Auditing, 14(1), 22-39.

Rukajat, A. (2018). Pendekatan Penelitian Kualitatif (Qualitative Research Approach). Deepublish.

Wella, S. (2021). Pengaruh Kualitas Pelayanan Pajak dan Kepatuhan Membayar Pajak Terhadap Motivasi Membayar Pajak Bumi dan Bangunan (PBB) pada Keluarahan Pasar Merah Timur. Sekolah Tinggi Ilmu Ekonomi Eka Prasetya.

Widyaningsih, W. (2011). Efek ekstrak etanol rimpang temugiring (Curcuma heyneana val) terhadap kadar trigliserida. Jurnal Ilmiah Kefarmasian, 1(1), 55-65.

Yusnidar, J. (2015). Pengaruh Faktor-Faktor Yang mempengaruhi kepatuhan wajib pajak dalam melakukan pembayaran pajak bumi dan bangunan perdesaan dan perkotaan (studi pada wajib pajak pbb-p2 Kecamatan Jombang Kabupaten Jombang). Jurnal Mahasiswa Perpajakan, 4(1).

e-mail:irfanfatony@gmail.com 